\title{
Socioeconomic status, value, and response to number
}

THOMAS M. NELSON ${ }^{1}$ AND EUGENE C. LECHELT ${ }^{2}$

UNIVERSITY OF ALBERTA

An experiment was designed to study the role of sensory, empirical, and motivational variables in number discrimination of coin or slug displays having equal luminance. It was found that groups of children, differentiated on the basis of economic status, social class, and availability of money but equated for knowledge of purchasing power of money, respond in identical fashion when the number of slugs or coins viewed is within the "span of attention," i.e., when response is at a sensory level. Differences between groups of children appear when the number of coins (but not slugs) in a display are so many as to fall outside the child's "span of attention," thus requiring the additional utilization of a judgmental framework in ascertaining the "manyness" of a display. The less favored socioeconomic group coin estimates were significantly greater than those of the more favored. When response data are expressed as numerosity functions, the operation of motivational factors may be differentiated algebraically. At a theoretical level, it appears that motivational and sensory explanations are both true, providing they are restricted to definite and appropriate ranges of stimulus number and type.

Recent years have seen attempts to demonstrate effectively the existence of autism via the operation of personality and social variables within the visual process (Levine, Chein, \& Murphy, 1942; Murphy, 1947; Piaget, 1930). The majority of studies have been concerned with the role of what has been called "value" in vision (Ansbacher, 1937; Bevan \& Dukes, 1951; Bruner \& Goodman, 1947; Carter \& Schooler, 1949; Dukes, 1955; Dukes \& Bevan, 1952; Gilchrist \& Nesberg, 1952; Haigh \& Fiske, 1952; Klein, Schlesinger, \& Meister, 1951; Luft, 1957; McCurdy, 1956; Pepitone, 1950; Postman, Bruner, \& McGinnies, 1948; Rock \& Fleck, 1950; Sherif, 1935; Tajfel, 1957, 1959; Tajfel \& Caswasjee, 1959; Tajfel \& Winter, 1963; Vernon, 1955).

The work of Bruner and Goodman (1947) gave the greatest impetus to "value" research by demonstrating an interaction of monetary value and size estimation. But their study has been sharply criticized on methodological grounds and has been repeated several times with varying and sometimes conflicting results (Carter \& Schooler, 1949; Bruner \& Rodrigues, 1953; also see Tajfel, 1957).

Some of the equivocalness over the operation of motivational factors in a visual process may be removed by defining and varying target "value" along a dimension other than size. This dimension should have several properties. First, it should be more consistently related to economic value than size: The size dimension of coins increases in the dime, penny, nickle, quarter, half-dollar order, while monetary value increases in another order. Second, it should be less susceptible to memorial influence than size: Size shows a large time order effect in that size comparisons of targets presented contiguously in the field result in different size values than successive comparisons (Bruner \& Rodrigues, 1953; Minnaert, 1954).

These requirements can be perhaps adequately met by varying targets of fixed value along the dimension of number; monetary value and physical magnitudes vary concomitantly when a single type of token is changed in number (Ansbacher, 1937). An added advantage of using number is that the results could be interpreted as a legitimate extension of a respected body of data constituting research into mechanisms limiting the "span of attention" (Casperson \& Schlosberg, 1950; Femberger, 1921; Glannville \& Dallenbach, 1929; Graham, 1951; Hamilton, 1859; Hunter \& Sigler, 1940; Jevons, 1871; Miller, 1956; Oberly, 1924; Stevens, 1951; and Porter \& Wiseman, 1965).

The design evolved relates sensory, social, cultural, and motivational variables to children's discrimination of number in displays possessing differing levels of monetary value. The hypotheses specifically tested are the following: (1) Reliable differences in numerosity perception will not occur between low-socioeconomic and high-socioeconomic children on the basis of monetary value when the number of objects viewed does not exceed some critical number. That is, no differences in response are expected when the number of objects is within the "span of attention," such discrimination having an essentially sensory basis. (2) The monetary value of targets will produce a numerosity bias in a constant direction when the number of targets exceeds a critical number. Discrimination of number beyond the "span of attention" reflects, to a far greater extent, the use of higher, judgmental processes through which the inherent value of objects can be influential in ascertaining their numerousness. (3) Low-socioeconomic children will differ increasingly from high-socioeconomic children as the number of objects possessing monetary value exceeds the discrimination power of the sensory pathway. Further, this difference will be in the direction of overestimation. It is to be expected that children from a less favored socioeconomic background and demonstrating a greater "need" and preoccupation with value as money (see Subjects section) will, because of the relevance of value objects, overestimate the number of objects possessing value compared with children from a more favored socioeconomic background who demonstrate a lesser "need" and preoccupation with value (money). Such is also the case when value is manipulated within the context of size estimation (Bruner \& Goodman, 1947; also see Tajfel, 1957, 1959; and Tajfel \& Caswasjee, 1959). (4) No differences will occur between socioeconomic groups when "nonvalue" targets (slugs) are viewed under any condition of number. Unfamiliar, "nonvalue" targets (slugs) would essentially be neutral or at least possess an equal amount of relevance for children from differing socioeconomic backgrounds.

\section{METHOD}

Subjects

Forty (40) third graders without visual difficulties and attending two public schools in the city of Edmonton, Alberta, served. Age was approximately normally distributed within a range of 7 years 9 months to 9 years 5 months. Mean age was 8 years 6 months.

Selection was undertaken to provide two $S$ groups. One group was less favored (LF) in a socioeconomic sense. The LF group was defined by (1) residence in a low-income area of the city, (2) identification by the classroom teacher of the individual as a member of the class of the poorer, and (3) familiarity with the 
purchasing power of money ("value") but without money ("means") being readily available. The other group was more favored (MF), differing from the LF on the basis of location of residence, membership in the upper middle class, and availability of money. Groups were identical with regard to knowledge of the purchasing power of money.

Groups were assembled using specific procedures. Based upon a recent demographic study, residence for LF was established by choosing a large group of Ss from a school in a low-income section of the city and MF from a school situated in an "upper-middle" income area. Class membership was established through teacher evaluation. Teachers were asked to select, from the larger sample representing income areas, a group of children clearly belonging to "poor" and "well-to-do" classes depending upon the school location (i.e., "low" or "high" economic area of the city).

Practical sophistication with respect to the value of money was determined and used to equate "high need" and "low need" children. On the basis of responses made to a questionnaire, all $40 \mathrm{Ss}$ finally chosen were considered equally familiar with the purchasing power of money.

LF and MF groups differed importantly, however, with respect to financial need. This was established using an open-ended-type questionnaire. ${ }^{3}$ The 20 LF Ss finally selected clearly indicated that they demonstrated a greater need for money relative to the $20 \mathrm{MF}$ group.

Individuals from both LF and MF groups assigned to the "value" continuum were exposed only to dimes throughout the entire procedure. Those assigned to the "nonvalue" continuum were shown only slugs. Thus, four $\mathrm{S}$ groups were employed: An MF viewing dimes, an MF viewing slugs, an LF viewing dimes, and an LF viewing slugs. The four groups will be referred to henceforth as MFD, MFS, LFD, and LFS, respectively.

Ss in all groups were also equated on the basis of class performance, teacher evaluation, and available $1 Q$ measurements.

\section{Apparatus and Equipment}

Research was conducted in all-purpose school roorns, modified to produce an experimental setting without incidental illumination.

The apparatus consisted of two units. Unit " $A$ " was comprised of a field stop, incandescent lamp light source, lens with adjustable focus, and a neutral density Wratten filter. Output from the photic source was controlled by a variac, and voltage was continuously monitored through a meter. Unit "B" consisted of a box fitted with a reduction screen whose frame was coated with a luminescent substance, glass plates angled to reduce stray illumination from the projected light source, a mirror mounted to image the targets (slugs or dimes) on the frontal plane, and a black velvet target surface.

New Canadian dimes and aluminum blanks (slugs) of similar size served as targets. The reflectance of the slugs was less than that of the dimes. Luminosities were equated using a procedure to be described in the next section.

\section{Procedure}

A general interview, during which time the questionnaire was administered, was conducted with each child prior to the actual running of the experiment. Seven days later the child served as a $S$.

Great care was taken in preexperimental instructions. Ss were first informed that they were to serve in an experiment determining "how well you can see." $\mathrm{E}$ continued conversation on site for approximately $3 \mathrm{~min}$ and said: "This is an experiment to find out how well you can see how many things there are when they are shown for just an instant or flash." $S$ was then taken to a table on which lay a cloth. When the cloth was removed $S$ saw 25 slugs or dimes, depending upon group assignment. E next stated: "Here are a lot of slugs (or dimes) that we are going to play with. Before we start I want you to look at them closely to see that they are 'only slugs' (or 'real dimes')." S was allowed a 30-sec conversation-free period to inspect and handle the slugs (or dimes). At the conclusion of this interval the following instructions were given: "I am going to put some of these slugs (or dimes) down in this box. I won't put all of them in. Sometimes there will be only a few and sometimes there will be many." Second, S was taken to the display box (Unit "B") There he inspected the apparatus and was shown how slugs were placed on the mat and reflected in the mirror. Third, $\mathrm{S}$ was seated behind the reduction screen, room lights turned off, and 120-sec dark adaptation followed. After adaptation all Ss were able to detect the blue luminescent frame of the reduction tunnel. E then said: "You should always look right at the center of the blue square on the other box. When I say 'ready,' I want you to look very hard because right after I say 'ready' I will show you some of the slugs (or dimes) and I want you to tell me how many you saw. You will not always be sure of how many there are because you will see them for just a flash. Remember, right after I say 'ready' I will show you the slugs (or dimes). Just as soon as you see them, tell me how many you think there were. Are there any questions?"
Each $\mathrm{S}$ was given one practice trial. A two-slug (or dime) pattern was shown; in all cases $\mathrm{S}$ correctly perceived the display. Intertrial interval was approximately $30 \mathrm{sec}$.

Random patterns of from 3 to 12 slugs (or dimes) were always shown. E formed these on the black velvet mat by dropping slugs (or dimes) to the surface. The only alteration made was to move all targets at least $1 / 2$ in. apart and, in the case of the dimes, to make certain all display dimes were either "heads" or "tails." The "heads" or "tails" characteristic of the display was therefore accidental.

Stimulus objects were equal in area, but reflectance from the dimes was greater than from the aluminum slugs. Since in the Bunsen- Roscoe law (Le Grand, 1957), time and intensity are reciprocal, it was necessary to reduce illumination for the dimes in order to keep luminance constant. Slug illumination was set at $13.7 \mathrm{c} / \mathrm{ft}^{2}$ $(46.31 \mathrm{~mL})$. Dime illumination was reduced to this level by adding a neutral density Wratten filter and making a final fine adjustment with the variac, a procedure that minimizes differences in spectral composition of the targets attributable to variations in temperature of the source.

The shutter was set to give an exposure period of $40 \mathrm{msec}$. Since exposure time was not an experimental parameter and intensities were low, no attempt was made to provide continuous field illumination between trials. The use of a brief exposure of low intensity precluded the presence of afterimages.

The area that the projector illuminated was adjusted so that when the shutter was open an area about $7 \times 6$ in. covering the $6 \times 5$ in. aperture on the face of the reduction tunnel was lighted. The viewing distance provided for a total visual angle of $1.9 \mathrm{deg}$ with each dime subtending $13 \mathrm{~min}$ 2 sec of arc.

Ten orders of presentation were employed with one $S$ in each of the four groups receiving one of these orders. Each order contained each level of number from 3 to 12 , three times. A total of 30 observations were recorded from each $S$ taking approximately $25 \mathrm{~min}$. Ss were asked periodically if they were tired or wanted to quit. In all instances, they said they wished to continue and appeared to maintain a high level of interest throughout the entire experiment.

\section{RESULTS}

Data were analyzed graphically and also statistically by means of analysis of variance, trend analysis, and Duncan's New Multiple Range Test, Plots relating numerousness and number show differences between numerosity response 


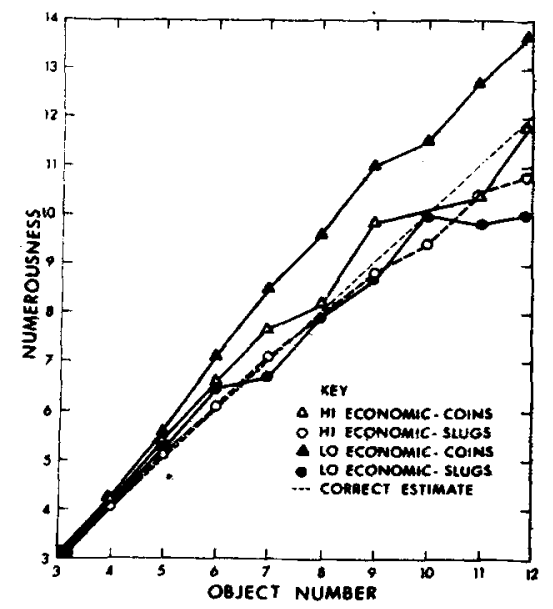

Fig. 1. Numerousness shown as a function of number of targets. Responses from four $S$ groups are depicted.

and actual target number. Figure 1 suggests (1) little evidence for differences between conditions when target displays are less than six in number, (2) that sizable differences occur between groups when number is greater than five, (3) that differences between subject groups appear only under the "value" condition, and (4) that it is the LFD group that gives higher average numerosity responses to displays of greater number. Thus, the graphic data appear to confirm the hypothesis in all respects. Analysis of variance of the effect of socioeconomic status, value, and number on numerosity discrimination showed that the main effects of less-favored children vs more-favored children, value vs nonvalue target type, and number level had a reliable effect on numerosity responses $(F=4.17$, df $=1,36, p<.05 ; F=11.84$, df $=1,36$, $p<.005 ; F=3.30$, df $=9,324, p<.005$, respectively).

The analysis of variance also revealed that one of the double as well as the triple interaction were reliably significant. The Value Dimension by Number interaction $(\mathrm{F}=4.56, \mathrm{df}=9,324, \mathrm{p}<.005)$ suggests that differences in numerosity responses made to the different levels of number employed is dependent on whether or not targets possess value, i.e., that levels of number affected numerosity responses to value targets differently than numerosity responses to valueless targets. The significant triple interaction $(\mathrm{F}=2.64$, df $=9,324, p<.005$ ) signifies, briefly, that the differences in numerosity responses to value and valueless targets are different for the less-favored group than for the morefavored group (see Table 1).

Using Duncan's New Multiple Range
Test, multiple comparisons were made among the treatment means to allow for more explicit findings. Number levels were paired in making the comparisons to reduce possible effects arising from heterogeneity of variance. The heterogeneity in response itself arose directly from stimulation by heterogeneous number levels.

Significant differences were not found among any of the four groups for Number Level 3 and 4. Level 5 and 6, however, resulted in a significant difference between two of the groups: LFD numerosity responses were significantly greater than the MFS numerosity responses $\left(R_{4}=.581\right.$, $p<.01$ ). At Number Level 7 and 8 , the LFD responses differed significantly from those of the LFS, MFD, and MFS $\left(R_{2}=1.02, \quad R_{3}=1.08, \quad R_{4}=1.09\right.$, $\mathrm{p}<.01)$.

The trend established at Level 7 and 8 continued over the remaining number levels. At Number Level 9 and 10 divergence between the LFD responses and the other three goups was even more reliable $\left(R_{2}=1.21, R_{3}=1.26, R_{4}=1.29\right.$, $p<.005)$. The differences occurring at the highest number level (11 and 12) are most reliable of all $\left(R_{2}=1.94, \quad R_{3}=2.01\right.$, $\left.R_{4}=2.06, p<.001\right)$.

Figure 2 plots the average deviation for each of the four groups on each of the five paired number levels. It further illustrates the divergent tendency of the LFD numerosity responses.

\section{DISCUSSION}

A $\log -\log$ transformation of numerosity response (R) and number levels $(S)$ is plotted in Fig. 3. This figure illustrates that when number is less than six $R=f(S)$. It can be seen that this condition holds for both curves representing the average slug numerosity responses averaged over the MFS and LFS groups taken together, and the average response of the LED group taken alone.

The evidence provided by Fig. 3 indicates that accurate discrimination of small number-subitizing (Kaufman, Lord, Reese, \& Volkman, 1949)-is in fact a psychophysical function and governed chiefly by activity taking place within the visual pathway. In suggesting that discriminations of small number are noncognitive, one must of course treat the use of number by the $S$ in response as sheerly an identification, naming, or categorization of the stimulus display, i.e., as a nominal use of number (Stevens, 1951). There is ample evidence suggesting this is possible (Price-Williams, 1962; Nelson \& Bartley, 1961; Piaget, 1952).

Figure 3 suggests that numerousness, the response ( $R$ ), is always partly a function of

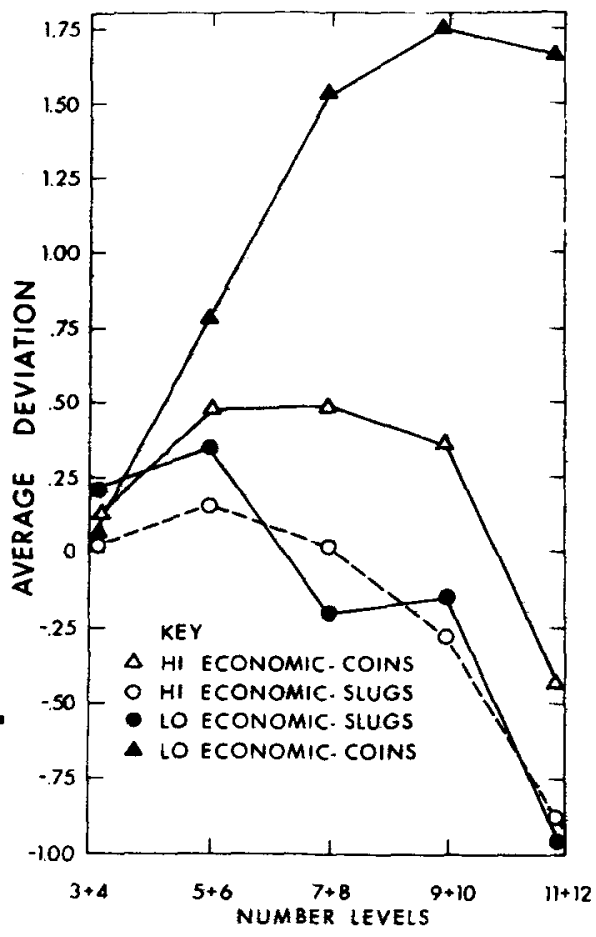

Fig. 2. Data transformed for purposes of Duncan's New Multiple Range Test. A verage deviation (number minus its numerousness) plotted against five categories of number. Responses from four $S$ groups are depicted.

number, the stimulus (S). By expressing this relationship quantitatively in terms of $\mathbf{R}=\mathrm{cSm}^{\mathbf{m}}$, where "c" is an arbitrary coefficient reflecting unit of measurement, and " $\mathrm{m}$ " is the actual inclination of the slope (Fig. 3), it is possible to give algebraic meaning to the slope and so express, in quantitative terms, differences in

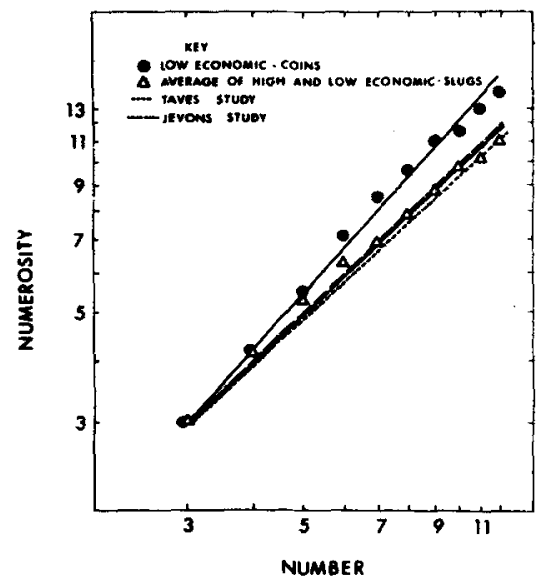

Fig. 3. Log-log plot of numerosity as a function of number. Responses from two $S$ groups are depicted. Results from research of Jevons (1871) and Taves (1941) are also fitted using free-hand technique. 
Table 1

Summary of Analysis of Variance of the Effect of Socioeconomic States, Value, and Number of Numerosity Discrimination

\begin{tabular}{lrrrrr}
\multicolumn{1}{c}{ Source of Variation } & $\begin{array}{c}\text { Sum of } \\
\text { Squares }\end{array}$ & df & Squares & F \\
\hline "Socioeconomic Status" & 25.0050 & & 1 & 25.0050 & $4.1733^{*}$ \\
"Value Dimension" & 73.9342 & 1 & 73.9342 & $11.8387^{*}$ \\
"Socioeconomic Status" X & 23.0352 & 1 & 23.0352 & 3.8445 \\
$\quad$ "Value Dimension" & 215.7024 & 36 & 5.9917 & $3.3026 * *$ \\
Error (a) & 27.0723 & 9 & 3.0080 & 1.8220 \\
"Number" & 14.9352 & 9 & 1.6595 & $4.5603 * *$ \\
"Socioeconomic Status" X "Number" & 37.5377 & 9 & 4.1079 & $2.6499 * *$ \\
"Socioeconomic Status" X "Value & 21.6810 & 9 & 2.4090 & 0.9108 & \\
$\quad$ Dimension" X "Number" & 295.1031 & 324 & 399 & & \\
Error (b) & 734.0060 & & &
\end{tabular}

*p.05;** p.005

numerosity response as a function of received considerable impetus through motivation factors.

The slope of the average slug numerosity responses is best satisfied by

$$
R=1.157 \mathrm{~S} \cdot 919
$$

where the two unknowns, "c" and "m," were simultaneously solved for. The exponential value obtained signifies a slight deviation from linearity (unity) and indicates numerousness to increase less rapidly than number. This corresponds well to the previous findings of Jevons (1871) and Taves (1941), which are also given in Fig. 3. The equation

$$
R=.904 S^{1.1119}
$$

describes the slope of the LFD group's average numerosity response and hence reflects motivation. The exponential value here again signifies a slight deviation from linearity with numerousness increasing more rapidly than number, which is opposite to what is ordinarily found in numerosity judgments. Differences in magnitude between the two exponents may be taken to describe, at a quantitative level, the influence of motivational factors.

The extent to which motivational properties influence number discrimination can also be expressed geometrically in terms of the angular separation between regression lines fitted to $\mathrm{Ss}^{\prime}$ responses. Figure 4 ilustrates the regression lines fitted to the slug numerosity responses averaged across both LFS and MFS groups and to the numerosity responses of the LFD group. Figure 4 also gives the equations for predicting numerousness ( $\left.Y^{\prime}\right)$ from number (X) under the "value" and "nonvalue" conditions. The angular separation between the regression lines was determined to be approximately $10 \mathrm{deg}$, with the "value" regression line again being slightly greater than linear and the "nonvalue" being slightly less than linear.

A general theoretical issue that has
Allport (1955) and Pastore (1949) has to do with whether "value," "need," and other so-called behavioral determinants directly affect primary sensory (neurophysiological) processes, or whether they produce an effect only upon cognitive processes. The data revive this controversy and show both positions partly right.

It seems clear from the data that when number was less than six, subject groups differing with respect to socioeconomic status did not differ in numerosity response, nor did the average numerosity response vary with target type. The same process apparently controlled discrimination of number for all groups. The fact that the "span of attention" is controlled in such discriminations by $I \times T$ strongly suggest pathway or sensory determination. Using Allport's (1955, pp. 345-357) terminology, one may therefore say that variations in cognitive or means value (degree of "positive relevance" an object has in a need-fulfilling situation) or variations in end value (degree of "motivational involvement" in a need-fulfilling situation) produce no effects under such conditons.

Motivational effects are apparently absent from those portions of the functions describing response to less than six target units. Since such discrimination is known to be under sensory (visual pathway) control (Hunter \& Sigler, 1940), these effects can be explained by reference solely to a time-intensity reciprocity law similar to that formalized for brightness as Block's law. Block's law in turn is paralleled on a tissue level by the Bunsen-Roscoe law, and the Bunsen-Roscoe law is customarily explained on the basis of transduction in the receptor cell, i.e., conversion of photic energy over time into frequency of discharge. Indeed, Hartline (1934) has contirmed the presence of this process at a neurophysiological level by making direct recordings from visual receptors in Limulus. Therefore, difficult as it may be intuitively, it seems clear that, where small numbers are discriminated, numerosity response is controlled by firing (discharge) rate.

This is not, of course, to say that veridical portions of the curves are a result of peripheral coding alone. The critical locus of this activity is doubtless at a receptor level for the Limulus but not necessarily at this level for the human. For example, Bartley and Nelson (1963) and Nelson, Bartley, and Jewell (1963) have related the Bunsen-Roscoe law to brightness and size discrimination in a manner that goes beyond sense-cell phenomenon. Explanation of small-number numerosity discriminations appears to require investigations into nervous activity initiated by a wider range of intensities and exposure times than have been used heretofore.

Beyond Number Level 6 things change. The rather abrupt change of direction beginning at Number Level 6 and continuing through 12 is evident in all curves. This appears to constitute a shift from the purely "sensory" to "judgmental", response levels since estimation of number is involved. Past researchers (Hunter \& Sigler, 1940; Miller, 1956) have considered the point of deflection is to delimit the "span of attention" and therefore to denote the point at which factors in addition to the sensory become operative in response. The fact that sensory process is insufficient is also shown by the breakdown of veridical discrimination. And it is interesting that the point of deflection in the LFD curve occurs at the point where this group began to differ reliably in numerosity response from the others. Since the difference is a LFD overestimation relative to the other S

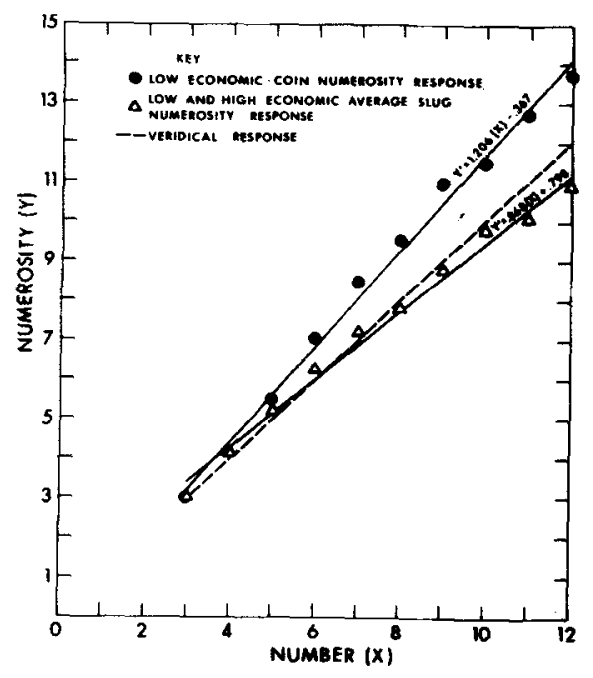

Fig. 4. Best fitting curves and formulas. Responses for two $S$ groups are depicted. 
groups, response is presumably conditioned by a constellation of motivational or cognitive properties somewhat unique to the LFD group.

\section{SUMMARY}

Two levels of "value," 2 levels of socioeconomic status ("need"), and 10 levels of number were combined into a 2 by 2 by 10 factorial experiment with repeated measurements to determine if motivational factors are effective in a child's discrimination of number. Half of the children in each of a "low economic" and "high economic" group (empirically defined) were shown briefly displays of economically valueless slugs varying in number from 3 to 12 and half were shown displays of dimes varying in like manner. Thus, four experimental groups were employed: one "low economic" shown dimes, one "low economic" shown slugs, one "high economic" shown dimes, and one "high economic" shown slugs. A constant time (exposure) period falling within the limits of the Bunsen-Roscoe law was used in order to have stimulation (number of targets) both within and beyond Ss' "span of attention."

It was found that when number is greater than 5, the "low economic" group numerosity responses to displays of dimes differ significantly from the three other groups. This difference increases in reliability as the number of display objects increases from 6 to 12 . Results confirmed expectations, and it was concluded that the judgmental processes of a child involved in number discrimination may be modified functionally by the presence of the motivational factors involved, but that responses controlled by processes of the visual pathway are relatively unaffected. Results were related to sensory, empirical, and motivational factors operating in visually mediated experience.

\section{REFERENCES}

ALLPORT, F. H. Theories of perception and the concept of structure. New York: Wiley, 1955.

ANSBACHER, H. Perception of number as affected by the monetary value of the objects. Archives of Psychology, 1937, No. 215.

BARTLEY, S. H., \& NELSON, T. M. Some relations between sensory end results and neural activity in the optic pathway. Journal of Psychology, 1963, 55, 121-143.

BEVAN, W., JR., \& DUKES, W. F. Value and the Weber constant in perception of distance. American Journal of Psychology, 1951, 64, 580-584.

BRUNER, J. S., \& GOODMAN, C. G. Value and need as organizing factors in perception. Journal of Abnormal \& Social Psychology, $1947,42,33-44$.

BRUNER, J. S., \& RODRIGUES, J. S. Some determinants of apparent size. Journal of Abnormal \& Social Psychology, 1953, 48, 17-29.

CARTER, L., \& SCHOOLER, K. Value, need, and other factors in perception. Psychological P.eview, 1949, 56, 200-207.

CASPERSON, R. C., \& SCHLOSBERG, $H$ Monocular and binocular intensity thresholds for fields containing 1-7 dots. Journal of Experimental Psychology, 1950, 40, 81-92.

DUKES, W. F. Psychological studies of value. Psychological Bulletin, 1955, 52, 24-50.

DUKES, W. F., \& BEVAN, W., JR. Size estimation and monetary value: A correlation. Joumal of Psychology, 1952, 34, 43-53.

FERNBERGER, S. W. A preliminary study of the range of visual apprehension. American Journal of Psychology, 1921, 32, 121-133.

GILCHRIST, J. C., \& NESBERG, L. S. Need and perceptual change in need related objects. Journal of Experimental Psychology, 1952, 44, 236-269.

GLANVILLE, D. A., \& DALLENBACH, K. M. The range of attention. American Journal of Psychology, 1929, 41, 207-236.

GRAHAM, C. H. Visual perception. In S. S. Stevens (Ed.), Handbook of experimental psy. chology. New York: Wiley, 1951. Pp. 868-920.

HAIGH, G. V., \& FISKE, D. W. Corroboration of personal values as selective factors in perception. Journal of Abnormal \& Social Psychology, 1952, 47, 394-398

HAMILTON, W. Lectures on metaphysics and logic, 1859,1 (Lecture XIV). Cited by Woodworth, R. S., Experimental psychology. New York: Henry Holt, 1938. Pp. 685-686.

HARTLINE, H. K. Intensity and duration in the excitation of single photoreceptor units. Journal of Cellular \& Comparative Physiology, 1934, 5, 229-247.

HUNTER, W. S., \& SIGLER, M. The span of visual discrimination as a function of time and intensity of stimulation. Joumal of Experimental Psychology, 1940, 26, 160-180.

JEVONS, W. S. The power of numerical discrimination. Nature, 1871, 3, 281-282.

KAUFMAN, E. L., LORD, M. W., REESE, T. W. $\&$ VOLKMAN, J. The discrimination of visual number. American Journal of Psychology $1949,62,498-525$.

KLEIN, G. S., SCHLESINGER, H. J., \& MEISTER, D. E. The effect of personal values on perception: An experimental critique. Psychological Review, 1951, 58, 96-112.

LECHELT, E. C. Effects of motivational factors on a child's discrimination of number. Unpublished MS thesis, University of Alberta, 1966.

LE GRAND, Y. Light, colour and yision London: Chapman \& Hall, 1957.

LEVINE, R., CHEIN, I., \& MURPHY, G. The relation of the intensity of a need to the amount of perceptual distortion: $A$ preliminary report. Journal of Psychology 1942, 13, 283-293.

LUFT, J. Monetary value and the perception of persons. Journal of Social Psychology, 1957 46, 245-251.

McCURDY, H. G. Coin perception studies and the concept of schemata. Psychological Review, 1956, 63, 160-168.

MILLER, G. A. The magical number seven, plus or minus two: Some limits on our capacity for processing information. Psychological Review, 1956, 63, 81-97.

MINNAERT, M. The nature of light and color in the open air. New York: Dover, 1954.

MURPHY, G. Personality: A bisocial approach to origins and structure. New York: Harper, 1947.

NELSON, T. M., \& BARTLEY, S. H Numerosity, number, arithmetization, measurement and psychology. Philosophy of Science, 1961, 28, 178-203.
NELSON, T. M., BARTLEY, S. H., \& JEWELL, R. M. Brightness from repetitive photic trains varying in pulse number and separation intervals: Sensory implications of the alternation of response theory, III. Joumal of Psychology, 1963, 56, 175-183.

OBERLY, H. S. The range of visual attention, cognition and apprehension. American Journal of Psychology, 1924, 35, 332-353.

PASTORE, N. Need as a determinant of perception. Journal of Psychology, 1949, 28, 457-475.

PEPITONE, A. Motivational effects in social perception. Human Relations, 1950, 3, 57 .

PIAGET, J. The child's conception of physical causality. New York: Harcourt, Brace, 1930.

PIAGET, J. The child's conception of number. London: Routledge \& Kegan Paul, 1952.

PORTER, V. F., \& WISEMAN, W. B. Visual discrimination of numerosity in rats as a function of number, size, and area. American Journal of Optometry and Archives of the American Academy of Optometry, March 1965, Vol. 42, No. 3.

POSTMAN, L., McGINNIES, E., \& BRUNER, J. S. Personal values as selective factors in perception. Journal of Abnormal \& Social Psychology, 1948, 43, 142-153.

PRICE-WILLIAMS, D. R. Abstract and concrete modes of classification in a primitive society. British Journal of Educational Psychology, $1962,32,50-61$.

ROCK, I., \& FLECK, F, S. A re-examination of the effect of monetary reward and punishment on figure-ground perception. Journal of Experimental Psychology, 1950, 40, 766-776.

SHERIF, M. A study of some social factors in perception. Archives of Psychology, 1935, No. 187.

STEVENS, S. S. Mathetmatics, measurement, and psychophysics. In S. S. Stevens (Ed.), Handbook of experimental psychology. New York: Wiley, 1951. Pp. 22-23.

TAJFEL, $H$. Value and the perceptual judgment of magnitude. Psychological Review, 1957, 64 192-204.

TAJFEL, H. Quantitative judgment in social perception. British Journal of Psychology, $1959,50,16-29$.

TAJFEL, H., \& CASWASJEE, S. D. Value and the accentuation of judged differences: $A$ confirmation. Journal of Abnormal \& Social Psychology, 1959, 59, 436-439.

TA JFEL , H., \& WINTER, D. G. The interdependence of size, number and value in young children's estimates of magnitudes. Journal of Genetic Psychology, 1963, 102, 115-124.

TAVES, E. H. Two mechanisms for the perception of visual numerousness. Archives of Psychology, 1941, No. 265.

VERNON, M. D. The functions of schemata in perceiving. Psychological Review, 1955, 62, 180-192.

\section{NOTES}

1. Address: University of Alberta, Edmonton, Alberta, Canada.

2. Now with the Department of Psychology, Princeton University, Princeton, New Jersey.

3. For example, "Mr. Jones doesn't have a car and he walks a long way to work every morning, even though a bus stops right in front of his house. Why do you think he walks to work?" A complete description of the materials and procedures employed is available elsewhere (Lechelt, 1966).

(Accepted for publication October 23, 1969.) 